\title{
A significant energy management control strategy for a hybrid source $\mathrm{EV}$
}

\author{
A. Geetha, C. Subramani \\ Department of Electrical and Electroincis Engineering, SRM Institute of Science and Technology, India
}

\begin{tabular}{|c|c|}
\hline Article Info & ABSTRACT \\
\hline Article history: & The conceptualization of Electric vehicles has been significant in solving \\
\hline Received Nov 23, 2018 & $\begin{array}{l}\text { the pollution due to the transportation problem. However, its design and } \\
\text { working has not yet been perfected and can be optimized. An effective model }\end{array}$ \\
\hline Revised Apr 29, 2019 & of the electric vehicle is the integration of batteries and supercapacitors. \\
\hline Accepted Jun 26, 2019 & $\begin{array}{l}\text { In this paper, the optimal sharing of energy between the battery and } \\
\text { the supercapacitor is provided by the Particle Swarm Optimization (PSO). }\end{array}$ \\
\hline Keywords: & $\begin{array}{l}\text { The results reveal that the proposed algorithm can better share the energy } \\
\text { between the hybrid sources. The simulations are carried out in MATLAB }\end{array}$ \\
\hline Battery & Simulink platform and the results obtained for ECE-15 driving cycle is \\
\hline Electric vehicle & \\
\hline Energy management & \\
\hline Particle swarm optimization & \\
\hline Supercapacitor & $\begin{array}{r}\text { Copyright }(0) 2019 \text { Institute of Advanced Engineering and Science. } \\
\text { All rights reserved. }\end{array}$ \\
\hline \multicolumn{2}{|l|}{ Corresponding Author: } \\
\hline \multicolumn{2}{|c|}{$\begin{array}{l}\text { C. Subramani, } \\
\text { Department of Electrical and Electronics Engineering, } \\
\text { SRM Institute of Science and Technology, } \\
\text { Kancheepuram, India. } \\
\text { Email: csmsrm@gmail.com }\end{array}$} \\
\hline
\end{tabular}

\section{INTRODUCTION}

Rapid use and depletion of natural resources and environmental problems such as Global warming, change of climate etc. have been major problems since the twentieth century and generation of energy by non-conventional resources is been heavily researched. Electric Vehicle (EV) is an up-and-coming solution for the problem of transportation and pollution [1-3]. The driving cycles comprises of many starts, stops and go conditions which seeks both average and instantaneous power supplies [4]. Even though there exist many advanced energy storage systems (ESS), among them battery performs better for average vehicle power demands. However, the shortcomings such as higher thermal heating and cost, lesser power density and working life time persists in batteries. Hence utilizing battery alone as an ESS doesn't provide efficient vehicle performances. Hybridization in electrical sources can resolve the above problems. An auxiliary ESS i.e., Ultracapacitor (UC) with longer life cycle and higher power density is hybridized with battery to support instantaneous vehicle power demands.

A significant improvement is proven in EVs when battery/UC hybridization is used [5-7]. With proper design and development, EVs not only exterminate pollution but can also be more efficient than conventional petroleum/diesel based vehicles. However, they are still in the process of research and still have many unresolved problems. Finding a potential energy source is one of these issues. Using a single source, such as a battery has certain disadvantages such as recharging, longevity, poor power density etc. One possible and promising solution for this problem is multi-source EV. Using both batteries and supercapacitors can diminish the disadvantages of both $[8,9]$. In this work, such a model with battery and supercapacitor has been designed.

The other problem is how to divide the power between the battery and the supercapacitor. The division must be optimal and efficient. For this, PSO control algorithm is being utilized. For the purpose 
of optimization first, the search space is restricted according to do the parameters and the conditions of the energy sources and the power demand of the vehicle. After the search space has been defined the PSO algorithm is implemented.

\section{POWER DYNAMICS}

According to the general power-sharing scheme $[10,11]$, for peak powers, the battery must be used and for continuous powers, the supercapacitor must be used. Also, for an efficient use of the energy sources there exists a energy distribution among the battery, the main source and supercapacitor, auxiliary source. This has been shown in the Figure 1. To simplify the simulation process, power losses are not considered in this work.

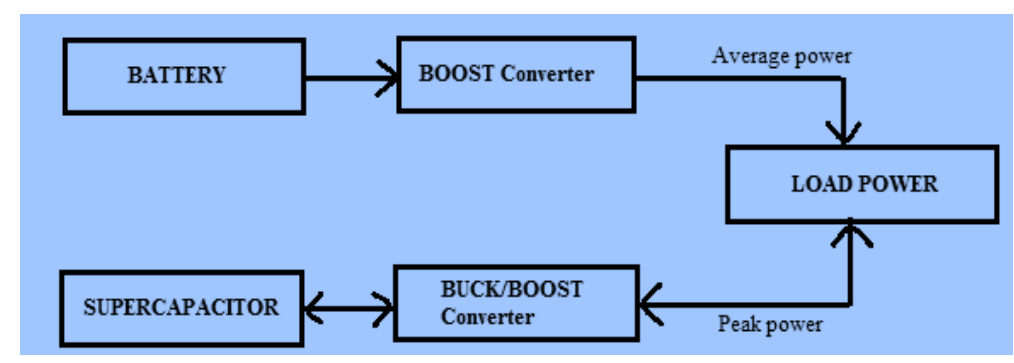

Figure 1. Power sharing scheme between battery and supercapacitor

The total power demand must be met by the battery and the supercapacitor together. Hence,

$$
P_{\text {total }}=P_{\text {Bat }}+P_{S C}
$$

Where $P_{\text {Bat }}, P_{S C}$ and $P_{\text {total }}$ are the power met by battery, power met by supercapacitor and the total power demand, respectively.

The battery power and supercapacitor power must be between their individual minimum and maximum values.

$$
\begin{aligned}
& P_{\mathrm{Bat}, \text { Min }} \leq P_{\text {Bat }}(t) \leq P_{\text {Bat,Max }} \\
& P_{\mathrm{SC}, \text { Min }} \leq P_{S C}(t) \leq P_{\mathrm{SC}, \text { Max }}
\end{aligned}
$$

The min power denotes the min power required for charging and the max power denote the max power for discharging among the storage devices.

The minimization objective function [OA] consider in this work is given in (4).

$$
J=\min \sum_{k=1}^{t=N}\left\{P_{\text {total }}(t)-\left(u_{B a t} * P_{B a t}(t)+u_{S C} * P_{S C}(t)\right)\right.
$$

Where $\mathrm{N}$ represents the period interval based on the driving cycle considered and $u_{B a t}, u_{S C}$ are the weight factors of the battery and supercapacitor. The constraints for the weight factors are given below:

$$
\begin{aligned}
& u_{B a t}, u_{S C} \in[-1,1] \\
& P_{B a t}=u_{B a t} * P_{B a t, \text { Max }} \\
& P_{S C}=u_{S C} * P_{S C, \text { Max }}
\end{aligned}
$$

The values of $u_{B a t}$ and $u_{S C}$ are determined by the PSO algorithm. The value of these weighing factors decides how much power will be drawn from the respective source. 


\section{PROPOSED CONTROL STRATEGY}

PSO control algorithm is a randomized method introduced by Kennedy and Eberhart. It is motivated by the societal behavior of fish schooling and bird flocking. Particles are randomly initialized and their position and velocity is updated with each iteration. The step by step procedure of the proposed algorithm is given below [12, 13]:

- Step 1: Parameter initialization such as swarm size, number of iterations, acceleration coefficients, inertia weight, limits of search space and velocity. The position of the particles is randomly initialized within the bounds of the search space.

- Step 2: The value of the objective function is found out at the particular time.

- Step 3: The values of the particle best location i.e. pbest and global best position i.e., gbest were attained.

- Step 4: The velocity and position of the swarm particle is restructured as given in below relations:

$$
\begin{aligned}
& V e l_{i}^{d}(t+1)=w V e l_{i}^{d}(t)+C_{l} R_{l}(t)\left(p_{\text {best }}^{d}(t)-p_{i}^{d}(t)\right)+C_{2} R_{2}(t)\left(g_{\text {best }}^{d}(t)-p_{i}^{d}(t)\right)(6) \\
& p_{i}^{d}(t+1)=P_{i}^{d}(t)+\operatorname{Vel}_{i}^{d}(t+1)
\end{aligned}
$$

Here $\operatorname{Vel}_{i}^{d}(t+1)$ - particle's velocity, $p_{i}^{d}$ - particle's position, $w$ - weight factor, $\mathrm{C}_{1}, \mathrm{C}_{2}$ acceleration coefficients and $R_{1}, R_{2}$ - random variables.

- Step 5: When the objective function is minimized and the maximum number of iteration has been reached the algorithm is stopped.

- Step 6: The optimal values of the parameters are obtained.

\section{RESULT DISCUSSION}

The block diagram of the main components and its connections are as shown in Figure 2. It consists of a Battery, Supercapacitor, Buck-Boost converter and a Boost converter. The nominal voltage of the battery is $24.6 \mathrm{~V}$ and its rated capacity is $6.6 \mathrm{Ah}$. The rated voltage of the supercapacitor is $16 \mathrm{~V}$ and its rated capacitance is $500 \mathrm{~F}$. The battery used here is Lithium-Ion type. Since lithium-ion batteries have a high specific energy and supercapacitors have high specific power, their combination is highly advantageous [8]. The proposed model is simulated for the ECE-15 urban drive cycle shown in Figure 3.

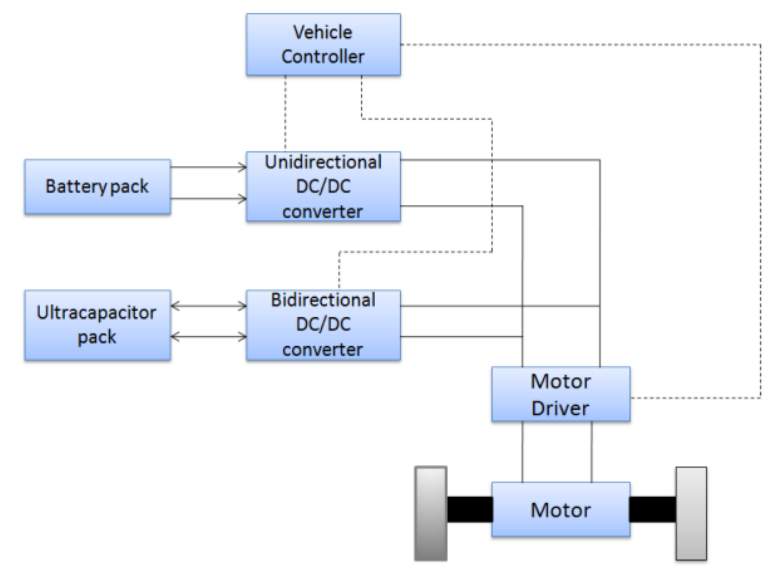

Figure 2. Simulink battery-supercapacitor model

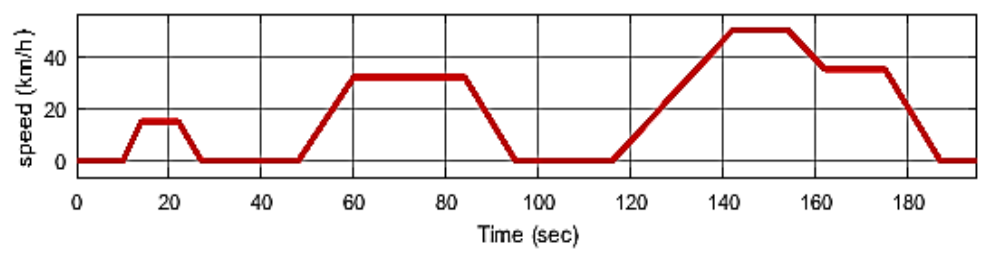

Figure 3. ECE drive cycle 
The total power demand was calculated according to the vehicle dynamics of the vehicle corresponding to the drive cycle. The demanded force is calculated by the use of below equations $[14,15]$. The force $(\mathrm{F})$ required to run the vehicle should overcome rolling resistance force $\left(\mathrm{F}_{\mathrm{ro}}\right)$, climbing force $\left(\mathrm{F}_{\mathrm{cl}}\right)$ and aerodynamic dragging force $\left(\mathrm{F}_{\mathrm{dr}}\right)$ as given in (8).

$$
\mathrm{F}=\mathrm{F}_{\mathrm{ro}}+\mathrm{F}_{\mathrm{cl}}+\mathrm{F}_{\mathrm{dr}}
$$

The force required to overcome the tire and road friction losses is $F_{\text {ro }}$ as represented in (9). Topological influences on the vehicle should overcome by $F_{\text {climb }}$ given in (10). Vehicle needs some energy to overcome the air friction on the frontal, rear and boundary area of the vehicle $F_{\text {drag }}$ as given in (11).

$$
\begin{aligned}
& \mathrm{F}_{\mathrm{ro}}=\mathrm{m}_{\mathrm{ve}} * \mathrm{~g}_{\mathrm{ac}} * \mathrm{C}_{\mathrm{ro}} \\
& \mathrm{F}_{\mathrm{cl}}=\mathrm{m}_{\mathrm{ve}} * \mathrm{~g}_{\mathrm{ac}} * \sin \propto_{\mathrm{in}} \\
& \mathrm{F}_{\mathrm{dr}}=\frac{\left(\rho * \mathrm{~A}_{\mathrm{fr}} * \mathrm{C}_{\mathrm{dr}} * \mathrm{v}_{\mathrm{ve}}\right)}{2}
\end{aligned}
$$

Here, $\mathrm{m}_{\mathrm{ve}}$ - vehicle mass $(\mathrm{kg}) . \mathrm{g}_{\mathrm{ac}}$ - acceleration due to gravity $\left(\mathrm{m} / \mathrm{s}^{2}\right) . \mathrm{C}_{\mathrm{ro}}$ - co-efficient of rolling resistance. $\propto_{\text {in }}$ - angle of inclination (radian). $C_{d r}$ - drag co-efficient. $\rho$ - air density in $\mathrm{kg} / \mathrm{m}^{3}$. $A_{\text {fr }}$ - vehicle's frontal area $\left(\mathrm{m}^{2}\right)$. $\mathrm{v}_{\mathrm{ve}}$ - speed $(\mathrm{km} / \mathrm{h})$.

As power depends upon the velocity, at each time interval the power demand changes as the velocity changes. To match the parameters of the model the power demand has been reduced by a factor of 10 . The battery and supercapacitor power was found by calculating the values of $u_{B a t}$ and $u_{S C}$ at each time interval via PSO. The power was then manually fed to the power blocks of the battery and supercapacitor.

Figure 4 represents the power output and power required. As seen, the power output and power required are in almost perfect agreement with each other. Figure 5 represents the individual power output of the battery and the supercapacitor. Figures 6 and 7 represent the current, voltage and state of charge characteristics of the supercapacitor and battery respectively. For the battery, the SOC $\%$ is decreased from 100 to $95 \%$ and for the supercapacitor, the SOC $\%$ is decreased from $93 \%$ to $87 \%$.
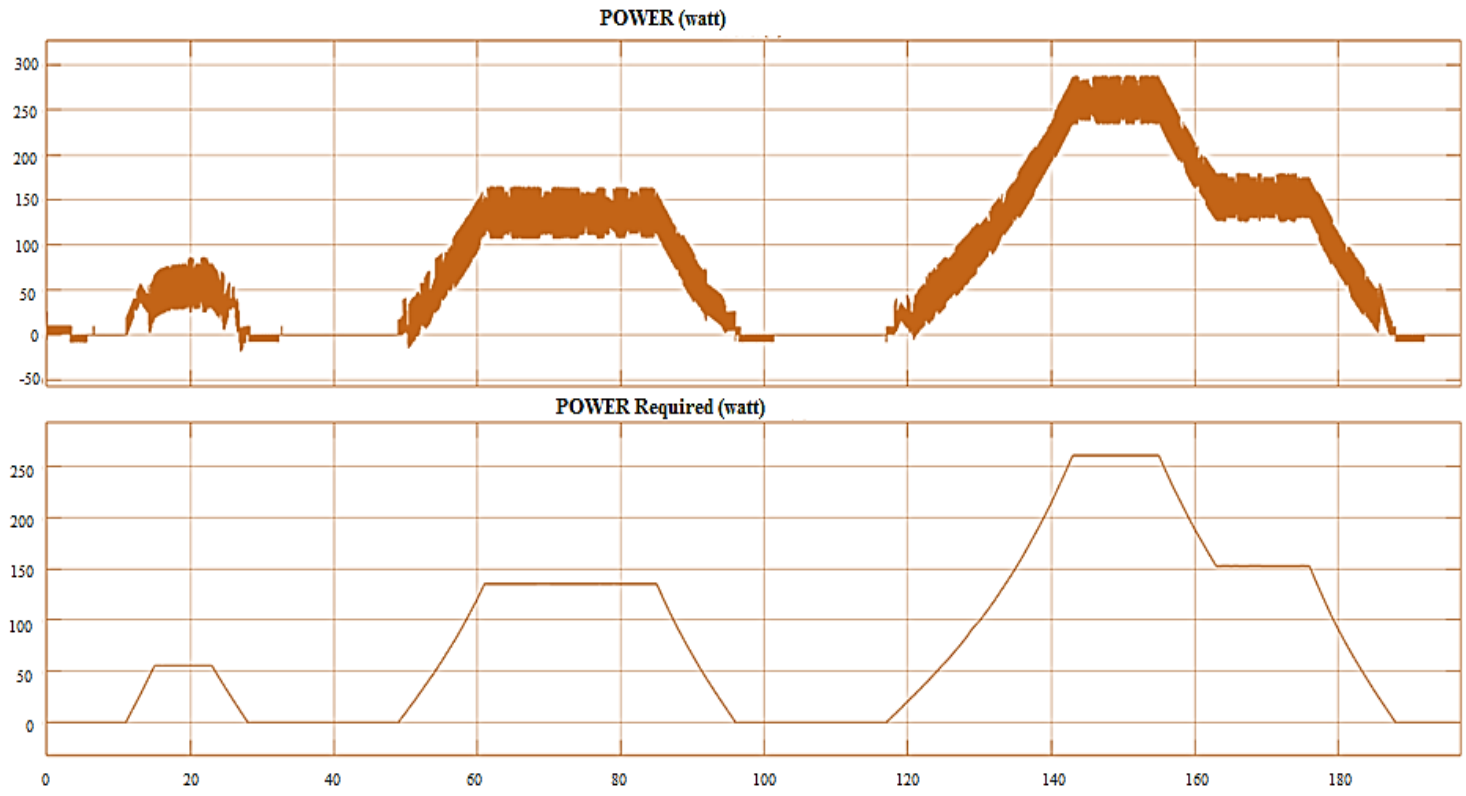

Figure 4. Power output and power required 


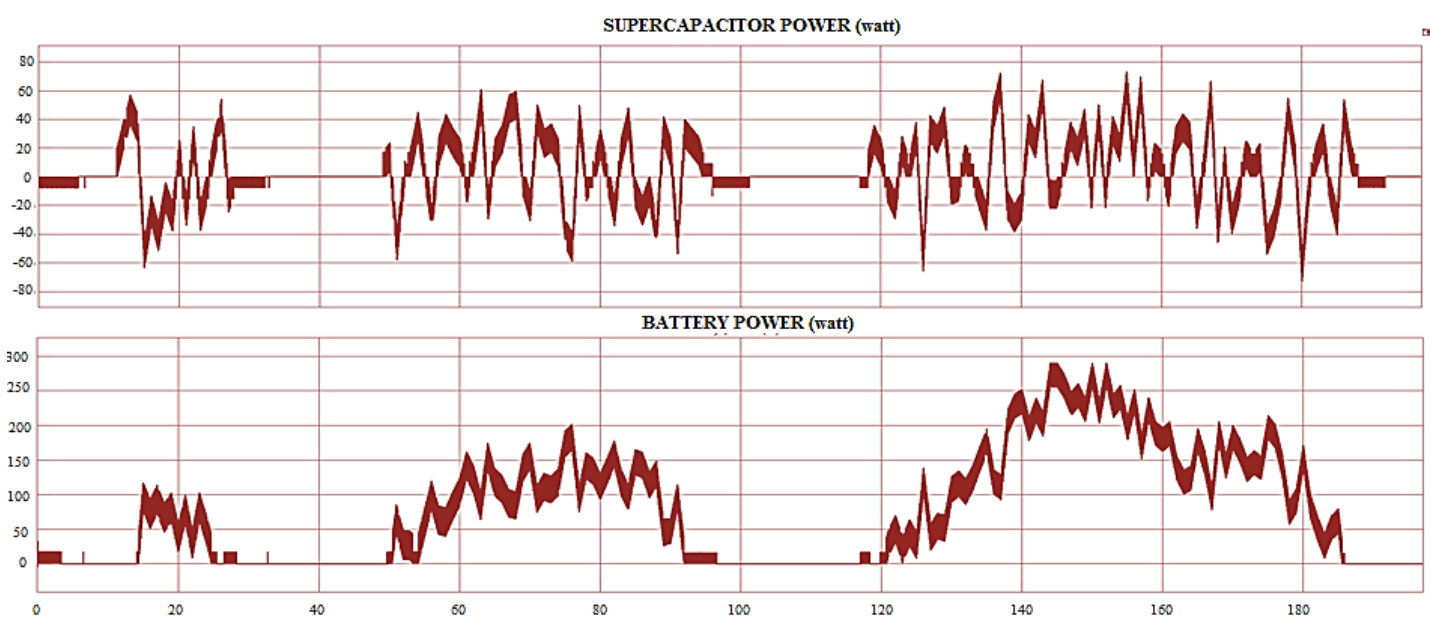

Figure 5. Supercapacitor and battery power
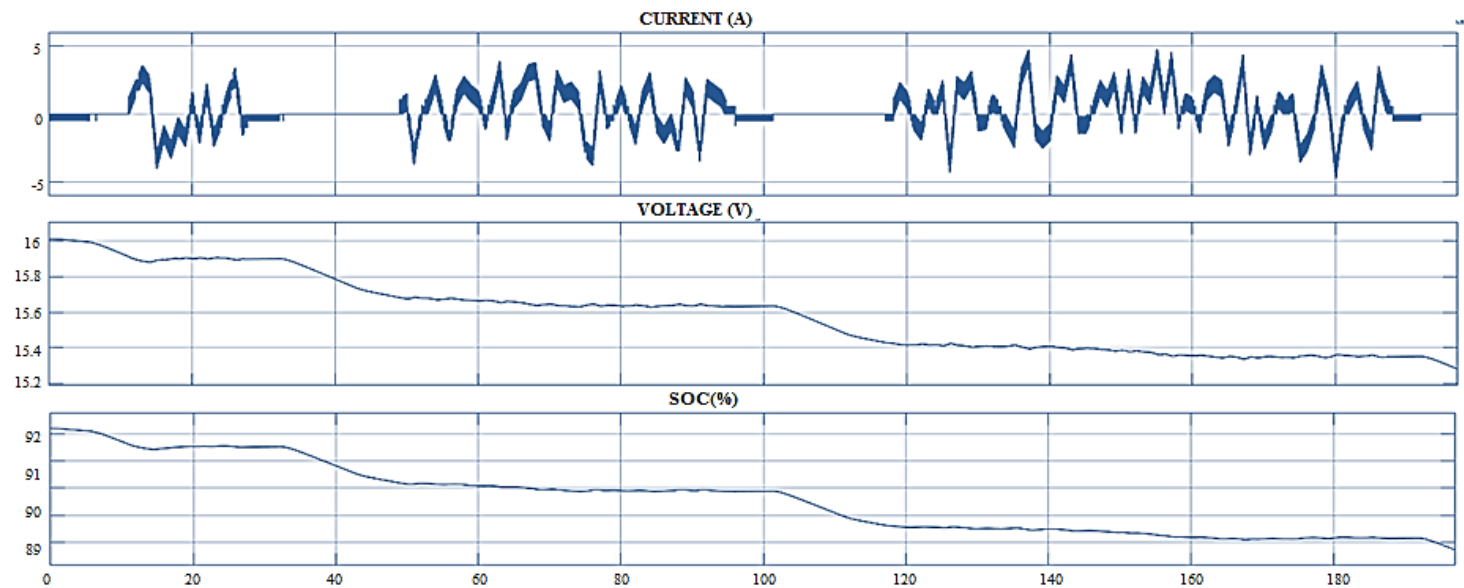

Figure 6. Current, voltage and SOC characteristics for the supercapacitor

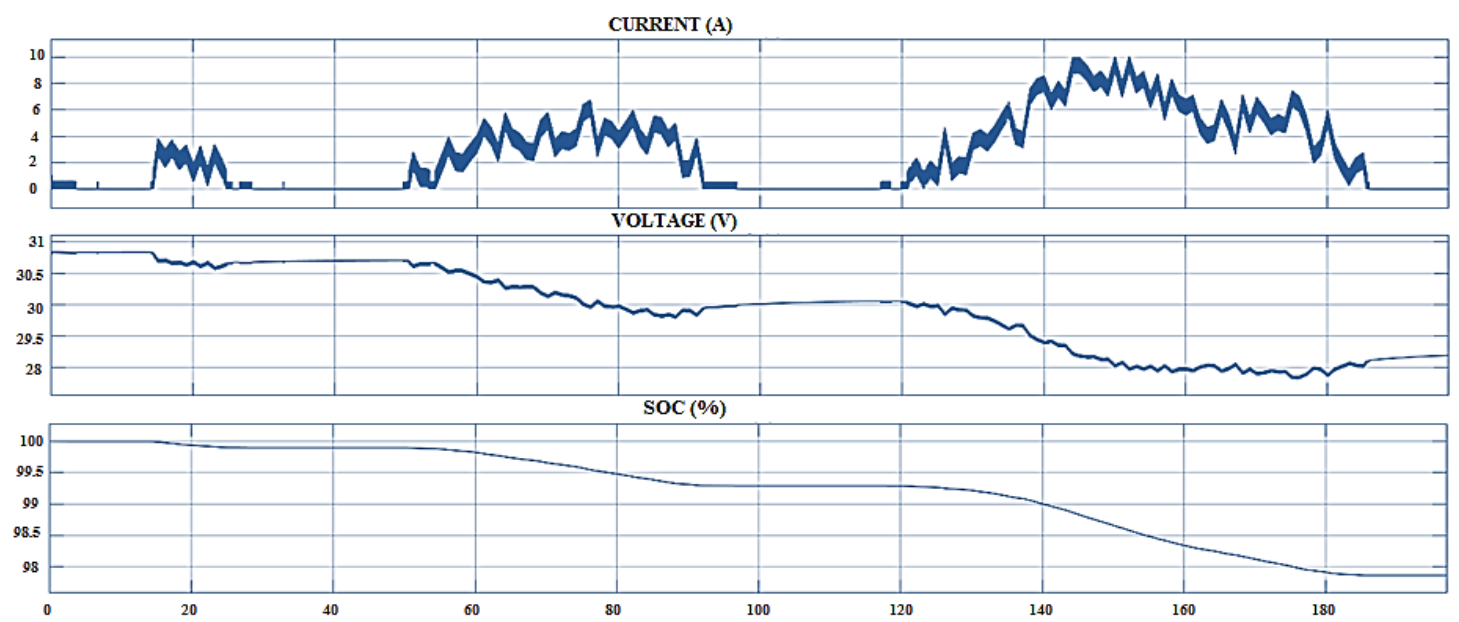

Figure 7. SOC, current and voltage characteristics for the battery

It should be noted that if the model were to have only battery as a source then the average current or battery stress would be much higher than the present model. In other words, by adding the supercapacitor the stress on the battery decreases significantly. 


\section{CONCLUSION}

The Electric Vehicle technology is developing a field of research and is crucial for solving the environmental problems. Energy management between different energy sources is an essential part of this research as presently no energy source can power the entire electric vehicle efficiently. Hence, in this work, the Particle Swarm Optimization technique was implemented for optimal energy sharing among the battery and the supercapacitor. As seen from results the proposed model works well for the ECE-15 Driving cycle. Similar control can also be achieved for other driving cycles.

\section{ACKNOWLEDGEMENT}

Authors like to thank SRM Institute of Science and Technology (SRM Selective Excellence), Kattankulathur, India for supporting this research work.

\section{REFERENCES}

[1] A. Geetha and C. Subramani, "A comprehensive review on energy management strategies of hybrid energy storage system for electric vehicles," International Journal of Energy Research, vol. 41, pp. 1817-1834, 2017.

[2] S. M. Lukic, et al., "Energy storage systems for automotive applications," IEEE Transactions on Industrial Electronics, vol. 55, pp. $2258-2267,2008$.

[3] Millo F, et al., "Real CO2 emissions benefits and end user's operating costs of a plug-in hybrid electric vehicle," Applied Energy, vol. 114, pp. 563-571, 2014.

[4] M. Staackmann, et al., "Dynamic driving cycle analyses using electric vehicle time-series data," in Intersociety Energy Conversion Engineering Conference, IECEC 1997. Thirty-second Annual IEEE, 1997, pp. 2014-2018.

[5] A. Kuperman and I. Aharon, "Battery-ultracapacitor hybrids for pulsed current loads: a review," Renewable and Sustainable Energy Reviews, vol. 15, pp. 981-992, 2011.

[6] A. Kuperman, et al., "Design of a semiactive battery-ultracapacitor hybrid energy source," IEEE Transactions on Power Electronics, vol. 28, pp. 806-815, 2013.

[7] J. Cao and A. Emadi, "A new battery/ultracapacitor hybrid energy storage system for electric, hybrid, and plugin hybrid electric vehicles," IEEE Transactions on Power Electronics, vol. 27, pp. 122-132, 2012.

[8] A. Geetha and C. Subramani, "An idea for students project work: Energy management in hybridization of energy sources for transportation application," International Journal of Electrical Engineering Education, pp. 1-19, 2018.

[9] Sanliang Zhang, et al., "Supercapacitors Performance Evaluation," Advanced Energy Material, vol. 5, pp. 1401401-1401419, 2015.

[10] L.C. Rosario, "Power and Energy Management of Multiple Energy Storage Systems in Electric Vehicles," PhD. Dissertation, Cranfield University, United Kingdom, 2007.

[11] Z. Song, et al., "Energy management strategies comparison for electric vehicles with hybrid energy storage system," Applied Energy, vol. 134, pp. 321-331, 2014.

[12] J. Kennedy, et al., "Particle swarm optimization," in International Conference on Neural Networks, 1995. ICNN 1995. Annual IEEE, 1995, pp. 1942-1948.

[13] Selim Koroglu, et al, "Energy Management System for Battery/Ultracapacitor Electric Vehicle with Particle Swarm Optimization," in International Conference on Recent Advances in Electrical Systems, Tunisia, 2016.

[14] T. D. Chan, and K. T. Chau, Modern electric vehicle technology, 1st ed.; Oxford University Press, 2001.

[15] M. Kamachi, et al., "Development of power management system for electric vehicle "i-MiEV"," in International Power electronics conference, IPEC 2010. Annual IEEE, 2010, pp. 2949-2955. 